\title{
LETTERS
}

\section{System-level change needed to support mental health disclosure}

I applaud Dr. Bernard on her powerful article disclosing her battles with depression. ${ }^{1}$ I agree that attention to mental health through disclosure to trusted colleagues, medical care, and saying "no" to some of the often-overwhelming opportunities in medicine is key. I also agree with Dr. Bernard that disclosure is challenging and that reprisals from regulators stigmatize mental health to the detriment of physicians.

For example, during the initial application for and annual renewal of a licence, the College of Physicians and Surgeons of Alberta requires disclosure of any "physical, cognitive, mental and/or emotional condition that is negatively impacting your work, or is reasonably likely to negatively impact your work in the future." First, the wording of this requirement is so incredibly broad that an argument could be made that any and all conditions must be disclosed. Second, there is no information provided on the implications of disclosure. Is it just for information? Mandatory health monitoring? Restrictions or refusal of licensure?
An American study ${ }^{2}$ found that $40 \%$ of physicians "reported that they would be reluctant to seek formal medical care for treatment of a mental health condition because of concerns about repercussions to their medical licensure." However, those working in a jurisdiction that required disclosure about only current impairment from a mental health condition were significantly less likely to be reluctant to seek care.

Regulatory bodies have the potential to support or to stigmatize physician mental health. If yours isn't doing the former, let them know.

\section{Mike Benusic MD MPH}

Family physician and resident in public health and preventive medicine, University of Toronto, Toronto, Ont.

- Cite as: CMAJ 2020 January 27;192:E99. doi: $10.1503 / \mathrm{cmaj} .74071$

\section{References}

1. Bernard, C. Disclosure. CMAJ 2019;191:E1196-7.

2. Dyrbye LN, West CP, Sinsky CA, et al. Medical licensure questions and physician reluctance to seek care for mental health conditions. Mayo Clin Proc 2017;92:1486-93.

Competing interests: None declared. 